\title{
THE TRANSPARENCY TROPE: DECONSTRUCTING ENGLISH ACADEMIC DISCOURSE
}

\author{
Karen Bennett
}

\begin{abstract}
English Academic Discourse has always presented itself as a neutral vehicle of objective fact. Through the use of clearly defined terms and straightforward syntax, and the studied avoidance of forms of overt manipulation of the reader, it claims to offer a transparent window onto some pre-existing external reality. Today, however, most linguists agree that objectivity is a linguistic construct, achieved by the systematic use of grammatical forms such as nominalizations and the passive voice which mask human agency. Similarly, it is now generally understood that even the most positivistic science texts contain a certain amount of rhetorical manoeuvring designed to convince the reader of the truth value and utility of the claims made. This paper draws upon a range of linguistic, historical and philosophical sources to question this discourse's status as the hegemonic vehicle of knowledge in the modern world.
\end{abstract}

\section{Key words}

English Academic Discourse, transparency, rhetoric, science, epistemology

\section{Introduction}

English Academic Discourse (EAD) is slowly but surely becoming the only acceptable vehicle for knowledge in the modern world. Twenty years ago, scientific articles were still routinely produced and published in languages like French, German and Russian and circulated widely within their respective areas of influence. But since the turn of the millennium, this has changed. English has emerged as the unequivocal lingua franca of academia, and as a result, publishing in 'international journals' is now synonymous with publication in that language (Lillis \& Curry 2010: 6).

Within English, there has been a similar erosion of difference, this time between areas of knowledge. The scientific paradigm, with its close links to technology, industry and business, enjoys unparalleled prestige in modern society $^{1}$ to the extent that the humanities and social sciences are now under considerable pressure to assimilate to it in order to be taken seriously by funding bodies. One of the consequences of this is that the discourse used in subjects like history, literary studies and sociology is fast becoming indistinguishable from that of the exact sciences. Predicated upon the understanding that it is possible 
to transmit facts about the world in an entirely objective manner, this hegemonic discourse ostensibly eschews all authorial manipulation and uses clearly defined terms and straightforward syntax to create an effect of transparency. Meanwhile, the alternative modes of writing that appeared in the late twentieth century precisely to critique this premise (such as the emancipatory écritures of feminism and postcolonialism, the dense opaque textuality of Critical Theory, and the alternative discourses of qualitative research ${ }^{2}$ ) seem to have retreated into ghettos, no doubt deterred by unsympathetic reviews suggesting that they were a passing phase that has since been outgrown. ${ }^{3}$

This process of uniformization has been accompanied by the development of lucrative language industries for which the discourse is a commodity to be packaged and sold. Style manuals and course books are churned out in their hundreds in response to an ever more differentiated market; courses in English for Academic Purposes are organised in universities around the world; and there are increasing numbers of journals and conferences dedicated in large part, or even exclusively, to EAD. As an entity, it is now so clearly defined and so widespread that for many it is inconceivable that knowledge could be construed in any other way.

However, as this article attempts to show, EAD's prestige rests, at least in part, upon a premise that is fundamentally false. The claim that plain straightforward prose offers a transparent window ${ }^{4}$ onto some independently existing reality was first made during the $16^{\text {th }}$ and $17^{\text {th }}$ centuries to discredit the text-based learning of the Scholastics and provide grist for the 'new science' that was then in the ascendancy. But, as I attempt to show in this article, objectivity is itself a linguistic construct and the 'facts' that the discourse purports to transmit are not so much discovered as created. There is also a great deal of rhetoric involved in the presentation of scientific knowledge, despite the negative connotations accruing to the word within the scientific paradigm. Indeed, the trope of transparency may itself ultimately prove to be a rhetorical device, designed to reinforce the status of a particular form of knowledge at the expense of others.

This article draws upon a range of linguistic, historical and philosophical sources to question EAD's status as the hegemonic vehicle of knowledge in the modern world. After a brief review of its structure and history, it proceeds to deconstruct some of its central premises, before closing with a reflection about why the transparency trope has persisted for so long.

\section{What is English Academic Discourse (EAD)?}

Nowadays it is fashionable to talk about academic discourses in the plural, in order to emphasise the differences that undoubtedly exist between different 
disciplinary areas and academic genres (e.g. Hyland 1999b, 2000). However, I shall argue in this article that these are only nuances or surface variants of a discourse that is so ubiquitous in the Anglo-Saxon world that it is scarcely viewed as a discourse at all. This is because all mainstream academic writing in English is grounded in the same epistemological principle, namely the belief in the existence of an extralinguistic reality that can be unproblematically accessed and described using plain language.

This was made clear by a recent survey of academic style manuals (Bennett 2009), which revealed a remarkable consensus as to what constituted good academic writing in English. Apart from a few minor variations between disciplines (such a preference for personal or impersonal forms), all but one ${ }^{5}$ of the works consulted made the same recommendations. These may be summarized as follows:

a) General Principles:

- clarity, economy and precision (avoiding vagueness, verbosity, circumlocution)

- structured rational argument supported by evidence (avoidance of dubious persuasive techniques)

- fact clearly distinguished from opinion

- caution and restraint about claims (use of hedging devices, etc.)

- incorporation of theory through citation and referencing

b) Text Structure:

- text organised into sections: Introduction/Development/Conclusion (in the humanities and arts) Introduction/Method/Results/Discussion (in the empirical sciences)

- sections organised into paragraphs, each dealing with one particular idea

- hierarchical structure at all ranks, with general statement of theme followed by development

- coherence created by thematic progression and made explicit through signposting

- cohesion (through use of linkers, back- and forward referencing, ellipsis, etc.)

c) Sentence Length and Structure:

- complete sentences, each containing one main point, with straightforward syntax

- sentences relatively short or varied in length, rarely containing more than about 40-50 words 
d) Lexis:

- technical terminology from discipline (in the sciences)

- lexis used denotatively with clear definition of key words (in the humanities)

- concrete terms rather than abstractions

The manuals were also united by a distrust of overt rhetoric. Many warned explicitly against the manipulation of the reader by means of emotive language, implying that the only licit forms of persuasion were straightforward demonstration and rational argument supported by evidence. Figurative language was also broadly discouraged, although in some cases with provisos for certain humanities subjects.

What are the epistemological presuppositions underpinning these prescriptions? First of all, the discourse clearly assumes that there is a world outside language that has an objective neutral existence (in the sense that it appears the same to everyone, irrespective of culture, language or background) and that this world is accessible through our senses (hence the importance of observation, experiment and measurement). It also assumes that language merely serves to label this pre-existing reality, which is why such emphasis is given to plainness and simplicity. These philosophies (positivism, empiricism and realism respectively) permeate Anglo-Saxon culture so thoroughly that most native speakers of English are not even aware that other perspectives exist. As Berman (1988: 110) pointed out in his book on the reception of structuralism and poststructuralism in the United States, "in America, the controversies are customarily within empiricism" (my emphasis).

Yet this theory of knowledge has not always been with us, and is historically contingent in the sense that it came into being at a particular time and in a particular cultural context. Let us now look a little closer at its origins.

\subsection{History of English Academic Discourse}

EAD can trace its genealogy back to the Scientific Revolution of the $17^{\text {th }}$ century, which was when the empiricist paradigm first began to assert itself in the modern world. Before that, knowledge, understood as philosophy, was believed to reside in words, and students would be trained in the use of language and exegesis of authoritative texts (scriptures and certain classical texts that had been assimilated into the system). According to Christian humanists like Erasmus, language was a civilizing force, which could move men to virtue and help promote peace, justice and liberty. Hence, eloquence was cultivated as an educational discipline and literary ideal, and abundant speech was valued as an indication of inner worth. 
In the Classical rhetorical tradition, which dominated the educational curriculum throughout the Renaissance period, there were several aspects to language that needed to be considered when preparing a text. In addition to the referential dimension (logos) there was also a moral dimension (ethos) and an emotive dimension (pathos). There were also three styles from which the orator could choose in accordance with his aim and his audience: the grand style, which aimed to arouse the audience to a state of heightened emotion and placed great emphasis on the aesthetic dimension with a vast repertoire of tropes and figures; the plain style, which, as its name suggests, was more austere; and a middle style that was somewhere in between the two.

It was in the $16^{\text {th }}$ century that this began to change and Rhetoric started to drop out of fashion in England. A movement developed known as Anti-Ciceronianism, which was critical of the rhetorical extravagances of the age and the tendency to cultivate style at the expense of content. Then, in 1620, Francis Bacon's Novum Organum laid out a programme for a new approach to knowledge that would focus on the things of the physical world rather than texts ('things not words'), using observation, experiment and inductive reasoning instead of the deductive variety favoured by the Scholastics. Crucially Bacon advocated the plain style of rhetoric as the only appropriate one for this new science, a call that was echoed by other significant figures of the period such as Ben Jonson, Hobbes and Locke.

When the Royal Society was formed in 1660 it made plain style a prerequisite, not only privileging content above form but also making this knowledge more democratic. As Thomas Spratt expressed it in his History of the Royal Society of 1667:

They have exacted from all their members, a close, naked, natural way of speaking; positive expressions clear senses; a native easiness: bringing all things as near the Mathematical plainness, as they can: and preferring the language of Artisans, Countrymen, and Merchants, before that, of Wits or Scholars.

It is no coincidence that many of these early English scientists were Protestants, as Robert Merton ([1938] 2001) asserted in his ground-breaking work on the sociology of science, for the plain style encoded Protestant values. In addition to the drive for simplicity and economy which they applied to all things in life, there was also the belief that plain unadorned language allowed direct access to the truth about things. That is to say, just as the Protestants preferred to do without the mediation of priests, icons and rituals in the religious sphere, so they eschewed rhetoric in the pursuit of knowledge, perceiving it as a form of obfuscation and manipulation. Over time, this led to the gradual elimination of 
Rhetoric from the school curriculum and the reification of the plain style in the scientific domain.

This Protestant belief that simple straightforward language offers a transparent window onto the Truth is still very deep-rooted in Anglo-Saxon culture and underpins not only EAD but also ongoing campaigns in other spheres (such as the Plain English Campaign in public administration and the Fight the Fog Campaign in the EU). It is even espoused by some linguists, such as the Systemic-Functional school which asserts the naturalness of the relationship between English grammatical structures and the outside world.

What exactly does it mean to make abstract writing 'plain'. Essentially what we are looking at is the relationship between semantics and grammar - between meaning and form. In 'plain' English, there is a 'natural' relationship between the two. Actions come out as verbs, descriptions as adjectives, logical relations as conjunctions and so on (Halliday \& Martin 1993: 218).

This is, however, a very Anglocentric perspective. For one, there are languages that do not distinguish between processes and participants ${ }^{6}$, which makes it difficult to argue that the relationship between semantics and grammar could ever be 'natural'. What is more, plain speaking is not valued in the same way everywhere. For example, in the Catholic countries of Southern Europe, where Scholasticism and Rhetoric continued to be taught long after they had been abandoned in Protestant North, the grand style became something of an identity marker and was cultivated systematically in schools and universities. Vestiges of this attitude can still be seen in the way academics from these countries write today.

In short, then, the discourse that is the hegemonic vehicle for knowledge in the modern world has not always been as widespread as it is today. It arose in a particular historical context in response to certain sociocultural pressures, and achieved dominance at the expense of other competing discourses. Its claim to transparency should thus be understood in the light of that struggle, as part of a move to gain control over what was to be considered as legitimate knowledge.

\section{Deconstructing English Academic Discourse}

This section will describe how English Academic Discourse, like all 'discursive formations' (Foucault 2002) actually constructs the world that it claims to reflect. Drawing upon classic works by linguists such as Halliday and Martin, Swales and Hyland, it focuses firstly on the question of objectivity, which is of course central to the scientific paradigm, and then on its corollary, the notion of the fact as something with indisputable truth value. 


\subsection{Objectivity is a linguistic construct}

According to Halliday and Martin (1993), modern scientific discourse was born in the $17^{\text {th }}$ century with the writings of Isaac Newton, who for the first time employed a linguistic device that would subsequently become central to the scientific worldview. That device was nominalization, the resource through which processes are reinterpreted into nouns by means of a mechanism called 'grammatical metaphorization'.

Where the everyday 'mother tongue' of commonsense knowledge construes reality as a balanced tension between things and processes, the elaborated register of scientific knowledge reconstrues it as an edifice of things. It holds reality still, to be kept under observation and experimented with; and in doing so, interprets it not as changing with time (as the grammar of clauses interprets it) but as persisting - or rather, persistence - through time, which is the mode of being of a noun (Halliday \& Martin 1993: 15).

Nominalizations serve two important purposes in scientific discourse. Firstly, by compressing complex phenomena into a single semiotic entity, they enable the construction of technical taxonomies. Secondly, they also permit information that has already been presented in clausal form to be concisely repackaged in subsequent sentences in order to create a discourse that moves forward in logical and coherent steps, each building on what went before. This of course has implications for the development of rational argument (which, as we have seen, is the only persuasive device that is truly accepted by the scientific paradigm), and for thematic progression (i.e. the internal organization of the text) (ibid.: 81-82).

With this repackaging of clauses into nouns, the focus of the discourse shifted away from the human observer to the things of the real world that formed the object of his study. This process was complemented by a second grammatical metaphor, the agentless passive, which came into fashion in the $19^{\text {th }}$ century (ibid.: 58). According to Ding (1998), this serves a number of different rhetorical functions: as well as making the discourse sound objective and impersonal, it also has a universalizing function by removing idiosyncrasy or doubt, enhances authority in the presentation of methods or results and emphasises the communality of the scientific project.

These two grammatical metaphorizations, then, effectively create the world that science claims to observe - a world of static things from which all subjectivity has apparently been excised. This is a very different world from that inhabited by the Renaissance humanists, for whom emotivity, aesthetics and ethics were 
essential components of knowledge. Yet nowadays even the humanities and social sciences aspire to transparency, producing a pared-down prose that does not problematize the act of knowing or the relationship between language and 'reality'. As Halliday and Martin (1993: 220) put it, after three hundred years of colonization by the discourse of science, there is now an "essential continuity between humanities and science as far as interpreting the world is concerned".

And yet, as I have already suggested, this transparency, like objectivity, is something of an illusion. For it is manifestly impossible to eliminate the interpersonal element altogether, and even the most positivistic science texts contain spaces for subjectivity, as in the construction of the authorial voice and stance, and the (covert) appeal to a conceptualized reader.

\subsubsection{The persistence of rhetoric}

As we have seen, the early scientists, like the Anti-Ciceronians that came before them, were highly sceptical of the way that words could be used to manipulate and aimed to overcome this by presenting their findings in plain simple language that would allow the facts to speak for themselves. Ironically, though, a great deal of rhetoric is actually required in order to achieve this effect, as Swales (1990: 112) has wryly pointed out. ${ }^{7}$ Indeed, if academic discourse were as straightforward as it makes itself out to be, there would be no need for the multitude of manuals and courses that exist to teach it. What these do, in fact, is to coach people in the rhetoric of science - that is to say, in techniques to persuade the scholarly community of the plausibility of their claims.

One example of rhetorical manoeuvring typical of the science can be found in the introductions to research articles. Swales (1990: 137-166) describes how these introductions serve primarily to generate interest in the topic and convince colleagues of the pertinence of the research. This so-called CARS ('Create a Research Space') approach involves three moves: i) establishing the broad territory for the study; ii) identifying a niche that has not yet been thoroughly investigated; and iii) occupying that niche. Thus, by presenting the study as responding to a need within a broader field of research, the introduction not only asserts the work's right to be taken seriously by other experts in the area, but also creates a motivation for it.

This is a form of self-promotion that has clearly been influenced by the discourse of marketing, as Mauranen (1993) has pointed out. And it is not unique to research article introductions. Hyland (2000: 63-84) has shown how similar strategies are present in abstracts, while Gross and Chesley (2012) have explored how they are systematically used in biomedical articles in order to 'sell' research that may actually be in breach of scientific ethics. Other rhetorical strategies may 
include the construction of expert identity in text books (Hyland 2000: 104-129) and of authority in $\mathrm{PhD}$ theses (Thompson 2012), dialogism in argumentative essays (Thompson 2001) and the use of attitude, relational and person markers (Hyland 1999: 104).

Also central to the scientific worldview is the use of epistemic modality ${ }^{8}$ to carefully modulate the degree of certainty to be attributed to a particular claim. These devices, which are as central to this discourse as nominalizations, ${ }^{9}$ serve a number of rhetorical functions. In addition to reflecting the organized skepticism that is one of cornerstone of scientific ethos, they also have a stance-creating function (Hyland 1999: 101), projecting authorial honesty and modesty (or, conversely, assurance and conviction), demonstrating respect for colleagues' views and readers' face needs, and indicating involvement in the topic and solidarity with readers. In the hands of a competent writer, hedging and boosting devices can actually reinforce claims to objectivity by carefully distinguishing between fact and opinion, as well as being used to strengthen one's own argument at the expense of an opponent's.

The exact epistemic device chosen (ranging from highly tentative forms such as 'it would seem...' to the categorical assertion of the universalising present 'it is') may provide an indication of the claim's precise status within the discourse community at a particular moment in time. As such, they contribute to the creation of facts. For although 'scientific facts' are still broadly understood within our empiricist paradigm to have objective truth value and to be gradually uncovered in a linear process of discovery, this is another dimension of the 'transparency trope' that does not stand up to scrutiny. As Hyland (1999a: 342) puts it:

The construction of academic facts is a social process, with the cachet of acceptance only bestowed on a claim after negotiation with editors, expert reviewers and journal readers, the final ratification granted, of course, with the citation of the claim by others and, eventually, the disappearance of all acknowledgment as it is incorporated into the literature of the discipline.

Let us look at this process in a little more detail.

\section{2 'Facts' are made not found}

A glance at the dictionary definitions of the word 'fact' reveals the pervasiveness of the positivist mindset in Anglo-Saxon culture. All the main English dictionaries persistently define the word in objective terms: "something that actually exists; reality; truth" (Dictionary.com); "a thing that is known or proved to be true" (Merriam-Webster); "an event or thing known to have happened or existed; a truth verifiable from experience or observation" (Collins). 
Indeed, this view is so entrenched in Anglo-Saxon culture that the 'fact creation' sounds like an oxymoron. Yet etymologically the word actually derives from the past participle of the Latin word for 'do' or 'make', and therefore means literally 'things made' (this is of course much more evident in the Romance languages where the word for 'fact' is similar to or even identical with the past participle of the verb).

When we consider the things that are considered to be incontrovertible 'facts' today (e.g. that the earth is round and goes around the sun; that man descended from the apes; that whales are mammals rather than fish), we realise that they have not always enjoyed this status. In many cases, the process of establishing them as facts was a long one and involved a great deal of conflict and sacrifice. Ultimately what was involved was convincing the powers of the period to subscribe to the interpretation - not always an easy matter when there were vested interests involved.

The situation is not so different today. The difference between a fact and a claim or theory is basically that the former has achieved a broad consensus amongst the scientific community to the extent that it is no longer seriously disputed; as such, it is entitled to appear in textbooks and encyclopaedias as a universal truth, unhistoricized by reference to an author, school or period (Kuhn [1962] 1996: 22; Hyland 1999a: 342). A theory, on the other hand, has not yet crystallized into a fact and is still being contested; hence, it will be attributed to a person or a school, and will not usually be expressed in the universalizing present tense. It is also less likely to appear in encyclopaedias or text books, but will instead be debated in academic journals as knowledge in the making.

A claim is the first stage in this process, the tentative broaching of a new take on a subject for the appraisal of the scientific community. The process of converting a claim into fact involves convincing that community that the theory is plausible, in the hope that it will attract followers. When the claim is first made, it is usually heavily hedged to protect the author's face if it should not find favour. If it does, it will gradually become less tentative reflecting the author's growing confidence about its plausibility.

Central to this process is the question of citation and referencing. The conventions concerning citation are today firmly established, as is shown by the general consensus on the subject in the style manuals (Bennett 2009: 51). Articles in the sciences and social sciences generally contain a literature review, usually in the introduction or as a separate section near the beginning, in which preceding and related research on the subject is systematically acknowledged; and the works cited will of course be fully referenced at the end or in footnotes/ endnotes. Within the body of the text, the work of others may be referred to using 
direct quote, paraphrase or summary, and the citation may be integral (when the researcher's name appears in the citing sentence) or non-integral (when it is given in parenthesis or as a footnote) (Swales 1990: 148).

Swales (1990: 150-154) and Hyland (1999a, 2000: 20-40) have described how the mode of quotation changes in accordance with the claim's precise status at any given moment. A new or controversial claim will tend to be quoted integrally using tentative reporting verbs (e.g. 'X suggests/argues/proposes'), which do not imply any commitment on the part of the reporting author. These verbs will then become stronger (e.g. 'shows/demonstrates/establishes') as the claim acquires support. The tense may also change. We might expect a reference to a very particular or circumscribed study to use the past tense in recognition of its specificity, while the present perfect may be used to suggest that the claim has a broader or continuing relevance or is still under discussion (Swales 1990: 151-154). There will also be a gradual move away from integral forms of citation to non-integral ones, which weaken the attribution. As we have seen, the ultimate accolade is the "disappearance of all acknowledgement" (Hyland 1999a: 342, quoted above) when the claim has become a 'fact' of the discipline, no longer circumscribable by tense or attributable to a particular individual.

However, for a claim to become fact, it also needs to be broadly coherent with the accepted body of knowledge that currently exists about that matter in the discipline (Kuhn [1962] 1996: 111). In a context in which EAD is the hegemonic medium, this also means subscribing to the empiricist paradigm encoded into its structure, an issue that becomes particularly pertinent for scholars whose research is carried out in other languages.

\section{Conclusion}

Clearly, then, the empiricist principles upon which EAD is based are deeply flawed. We cannot affirm with any certainty that there exists an objective extralingual reality that appears in same way to all and is gradually revealed through linear and communal process of discovery. Objectivity is a linguistic construct, achieved largely through use of nominalizations and impersonal verbs, and reinforced by devices such as epistemic modality which carefully distinguish between what is considered to be 'fact' and the author's subjective opinion.

Moreover, 'facts' as such have no independent existence, as we have seen: rather, they should be understood as claims or theories that have achieved consensus in the discourse community. Thus, it becomes clear just how central rhetoric is to the scientific enterprise. Indeed, it is only through effective rhetoric that researchers can convince their peers of the plausibility of their claims, as the publishers of the academic style manuals understand so well. 
We might wonder, then, why the trope of transparency is so persistently reiterated in those style manuals and elsewhere, and why, indeed, so many scientists and scholars buy into it. To some extent, Lyotard offered the answer back in 1979 in his famous book The Postmodern Condition. Science is ultimately a language game that is unable to verify its propositions through the methods traditionally attributed to it (Lyotard 1984: 23-27) and therefore has to resort to legitimizing narratives in order to justify its existence (ibid.: 27-31). The notion of some transcendental truth that lies outside language and is accessible through observation and experiment is thus one component of that narrative, a means of justifying its own existence.

To this may be added the effect of linguistic dominance. As we have seen, the discourse of science emerged in a particular historical context as a response to a particular set of sociocultural conditions, but acquired prestige through its associations with technology, industry and emerging capitalism. This allowed it to colonize other areas, creating calques of itself throughout the Englishspeaking world.

With the globalization of academia, it has now spread much further afield to become the dominant vehicle of knowledge worldwide. What is more, it is no longer restricted to science, but is also used increasingly for the social sciences and humanities, despite the fact that these subjects are linguistically and culturally embedded (De Swaan 2001) and therefore not easily transplanted to another medium. It is here that the trope of transparency truly comes into its own. As a figure of speech in "the rhetoric of anti-rhetoric" (White 1997: 27), transparency is EAD's unique selling point, the means by which it distinguishes itself from the academic discourses of other languages. That is to say, while those are perceived to be somehow partial and biased, or obfuscated by unnecessary adornment and ornamentation, it alone, with its plain diction and straightforward syntax, claims to offer a window onto 'reality' as it truly is.

The irony is, however, that the knowledge produced within the ambit of non-empiricist paradigms (such as those that have traditionally dominated humanities subjects in much of Continental Europe) often has to be radically rewritten in translation in order to acquire the veneer of transparency necessary for it to be acceptable to the Anglophone discourse community. ${ }^{10}$ Transparency is thus revealed to be a surface effect, achieved through the imposition of certain grammatical structures and lexical choices at the expense of others, formulations which are designed to sound reassuringly familiar to the target reader, but communicate very little because their universe of reference lies elsewhere. In the absence of a theory of knowledge that takes account of the way different languages mediate and structure our perception of the world, this discourse 
begins to seem less like a window onto the outside world than a reflecting mirror that constantly devolves our own image back to us.

\section{References}

Bennett, K. (2007a) 'Galileo's revenge: Ways of construing knowledge and translation strategies in the era of globalization.' In: Salaama-Carr, M. (ed.) Translation and Conflict, Special issue of Social Semiotics, 17/2, 171-193.

Bennett, K. (2007b) 'Epistemicide! The tale of a predatory discourse.' In: Cunico, S. and Munday, J. (eds) Translation and Ideology: Encounters and Clashes, Special ed. of The Translator 13/2,151-169.

Bennett, K. (2015) 'Towards an epistemological monoculture: Mechanisms of epistemicide in European research publication.' In: Plo, R. and Pérez-Llantada, C. (eds) English as an Academic and Research Language (English in Europe. Vol. 2). Berlin: De Gruyter Mouton.

Berman, A. (1988) From the New Criticism to Deconstruction: The Reception of Structuralism and Post-Structuralism. University of Illinois Press.

De Swaan, A. (2001) 'English in the social sciences.' In: Ammon, U. (ed.) The Dominance of English as a Language of Science: Effects on Other Languages and Language Communities. Berlin and New York: Mouton de Gruyter. 71-83.

Ding, D. (1998) 'Rationality reborn: Historical roots of the passive voice in scientific discourse.' In: Battalio, J. (ed.) Essays in the Study of Scientific Discourse: Methods, Practice and Pedagogy. Stamford: Ablex. 117-135.

Foucault, M. (2002, 1972 [1969]) The Archaeology of Knowledge. London and New York: Routledge.

Gross, A. and Chesley, P. (2012) 'Hedging, stance and voice in medical research articles.' In: Hyland, K. and Sancho Guinda C. (eds) Stance and Voice in Written Academic Genres. London and New York: Palgrave Macmillan. 85-100.

Halliday, M. A. K and Martin, J. R. (1993) Writing Science: Literacy and Discursive Power. Pittsburgh and London: University of Pittsburgh Press.

Hyland, K. (1999a) 'Academic attribution: Citation and the construction of disciplinary knowledge.' Applied Linguistics 20/3, 341-367.

Hyland, K. (1999b) 'Disciplinary discourses: Writer stance in research articles.' In: Candlin, C. and Hyland, K. (eds) Writing Texts: Processes and Practices. London and New York: Longman. 99-121.

Hyland, K. (2000) Disciplinary Discourses: Social Interactions in Academic Writing. Harlow: Longman.

Jelinek, E. and Demers, R. (1994) 'Predicates and pronominal arguments in straits Salish.' Language 70/4, 697-736.

Kuhn, T. S. ([1962] 1996) The Structure of Scientific Revolutions. $3^{\text {rd }}$ ed. Chicago: University of Chicago Press.

Lillis, T. and Curry, M. J. (2010) Academic Writing in a Global Context: The Politics and Practices of Publishing in English. London and New York: Routledge.

Lyotard, J.-F. (1984) The Postmodern Condition: A Report on Knowledge, transl. by Bennington, G. and Massumi, B. Manchester: Manchester University Press.

Mauranen, A. (1993) Cultural Differences in Academic Rhetoric. Frankfurt am Main: Peter Lang.

Merton, R. K. ([1938] 2001) Science, Technology and Society in Seventeenth-Century England. New York: Howard Fertig. 
Swales, J. M. (1990) Genre Analysis: English in Academic and Research Settings. Cambridge. New York: Cambridge University Press.

Thompson, G. (2001) 'Interaction in academic writing: Learning to argue with the reader.' Applied Linguistics 22/1, 58-78.

Thompson, P. (2012) 'Achieving a voice of authority in $\mathrm{PhD}$ theses.' In: Hyland, K. and Sancho Guinda, C. (eds) Stance and Voice in Written Academic Genres. London and New York: Palgrave Macmillan. 119-130.

White, H. (1997) 'The suppression of rhetoric in the nineteenth century.' In: Schildgen, B. D. (ed.) The Rhetoric Canon. Detroit: Wayne State University. 21-31.

Woods, P. (2006) Successful Writing for Qualitative Researchers. $2^{\text {nd }}$ ed. London and New York: Routledge.

(Endnotes)

1 Funding in many countries is increasingly ring-fenced for the so-called STEM subjects (sciences, technology, engineering and mathematics).

2 These include personal narratives, impressionistic tales, transcriptions of interviews, polyphonic texts, performative texts, hypermedia texts, etc. (cf. Woods 2006).

3 E.g. a review in the Times Literary Supplement of April 2008 describes an example of such discourse in a recent volume as "so old-fashioned, so locked in the critical indulgence of the late twentieth century, that it makes the work seem dated even as it comes fresh from the press" (Bate, J. 'Dampit and Moll,' TLS April 25 2008, 3-7).

4 The term 'windowpane prose' actually originated with George Orwell ('Why I Write?', first published in Gangrel, London, summer 1946), though the concept is part of a long tradition that stretches back through Quiller-Couch, Hazlitt and Swift to Ben Jonson and Francis Bacon. Cf. Section 2.1.

5 Woods, P. (2006/1999) Successful Writing for Qualitative Researchers. London and New York: Routledge. This work was contesting the dominant discourse by promoting alternative discourses for use in social science qualitative research.

6 Such as Salish and Wakashan (cf. Jelinek \& Demers 1994).

7 "The art of the matter, as far as the creation of facts is concerned, lies in deceiving the reader into thinking that there is no rhetoric, /.../ and that the facts are indeed speaking for themselves."

8 These include hedging devices to express caution or restraint (expressed typically by modal verbs, such as may/might/could; adverbials like 'perhaps', 'possibly' and main verbs such as 'it appears' or 'suggests' to replace more categorical alternatives) and boosters to express certainty (obviously, definitely, of course / will, must).

9 Robert Boyle employed hedging devices in his scientific treatises, a decade or so prior to the publication of the first Transactions of the Royal Society in 1665, and even reflected explicitly about this practice: “....in almost every one of the following essays, I /.../ speak so doubtingly, and use so often perhaps, it seems, it is not improbable and other such expressions, as argue a diffidence to the truth of the opinions I incline to..." (Works of the Honourable Robert Boyle in Six Volumes: Experimental Essays, 1772: 307, Rivington).

10 This question has been explored in more detail in Bennett 2007a, 2007b and 2015. 
Karen Bennett is Assistant Professor in Translation at the Universidade Nova in Lisbon. She specialises in translation studies, focusing on the transfer of knowledge across cultural and linguistic boundaries and the epistemological consequences of the dominance of English in this field. She has recently edited the volume The Semiperiphery of Academic Writing: Discourses, Communities and Practices (Palgrave, 2014) and is currently preparing a special issue of The Translator on the subject of International English and Translation (2017), coedited with Rita Queiroz de Barros.

Address: Prof. Doutora Karen Bennett, Dept. de Línguas, Literaturas e Culturas, Faculdade de Ciências Sociais e Humanas da Universidade Nova de Lisboa, Avenida de Berne 26-C / 1069-061 Lisboa. [e-mail: karen.bennett@netcabo.pt] 